\title{
Percutaneous endoscopic gastrostomy in a general hospital: prospective evaluation of indications, outcome, and randomised comparison of two tube designs
}

\author{
M Z Panos, H Reilly, A Moran, T Reilly, P J W Wallis, R Wears, I M Chesner
}

\begin{abstract}
The indications for percutaneous endoscopic gastrostomy (PEG) and patient outcome, were examined prospectively in the setting of a general hospital. In the course of 26 months, 76 patients underwent PEG (median age 62 years (range 18-99)) and were followed up for 6887 patient days. The median (range) duration of PEG feeding was 93 (3-785) days. The procedure was carried out for neurological indications in $76 \%$ of cases (stroke $51 \%$ ) and $53 \%$ of patients were severely malnourished (body mass index $<17$ $\left.\mathrm{kg} / \mathrm{m}^{2}\right)$ at the time of referral. In $12(16 \%)$ patients swallowing recovered and the PEG was removed after a median (range) of 55 days (20-150). Three (4\%) deaths were related to PEG (one oesophageal perforation, one haemorrhage, and one aspiration pneumonia). One patient developed peritonism and ileus, which resolved with conservative treatment. Minor complications included local sepsis $3 \%$, tube blockage $12 \%$, and tube connector leak 5\%. During seven days of observation, demands on nursing time for routine care of the PEG were the same as for nasogastric tube feeding, median (range) $21 \quad(4-42) \quad v \quad 16 \quad(4-40) \quad \mathrm{min} / \mathrm{day}$ respectively, but in about half the latter cases the tube had to be replaced at least once. Over 15 months, 29 patients were randomised to receive a $1.9 \mathrm{~mm}$ inner, 2.9 mm (9F) outer diameter Fresenius and 27 a $3.0 \mathrm{~mm}$ inner, $4.0 \mathrm{~mm}$ (12F) outer diameter Bower polyurethane tube and were followed for 2920 and 2388 patient days respectively. There was no difference in the insertion time (median (range) 20 $(10-45) v 24(10-45)$ min respectively) or number of patients with complications (three $v$ eight patients NS), although there were more minor mechanical problems (three $v 12, \mathrm{p}<0.01$ ) with the 12F tube. The internal anchoring device of the $12 \mathrm{~F}$ tube allowed its non-endoscopic removal, a method applicable to $16 \%$ of cases. No tubes were removed because of blockage. (Gut 1994; 35: 1551-1556)
\end{abstract}

Since it was first described in $1980,{ }^{1}$ percutaneous endoscopic gastrostomy (PEG) has been increasingly adopted and a number of studies have reported a low incidence of complications. $^{2-5}$ Increasing evidence of its safety and the wider availability of endoscopic skills make it likely that the use of PEG will spread in general hospitals. This study aimed to examine prospectively the indications for PEG in a district general hospital, to compare the demands on nursing resources of PEG versus nasogastric tube (NG) feeding, and to conduct prospective long term follow up of patients in order to determine patient outcomes of PEG. During the course of the study, we conducted a randomised comparison of two commercially available PEG tubes with lumens of different diameters.

\section{Patients and methods}

INDICATIONS FOR PEG AND DEMANDS ON NURSING RESOURCES OF PEG VERSUS NASOGASTRIC TUBE FEEDING

Birmingham Heartlands (previously East Birmingham) is a general hospital serving a resident population of 300000 . The study was conducted between November 1990 and January 1993. Inpatients and ambulant outpatients with impaired swallowing and a nutritional need for enteral feeding expected to exceed two weeks were considered for the study. Inclusion criteria for inpatients were an inability to tolerate a nasogastric tube on at least two occasions or the presence of an oesophageal abnormality contraindicating the use of a nasogastric tube. Outpatient inclusion criteria were either as above or a requirement for long term enteral nutrition for patients who opted for PEG in preference to a nasogastric tube for convenience and cosmetic reasons. Exclusion criteria were current chest infection, ascites, portal hypertension, active gastric ulcer, total gastrectomy, and uncorrected coagulopathy.

The endoscopic team were not, by and large, involved in ethical decisions as to whether PEG feeding was appropriate long term management. After referral for PEG, patients were assessed by two members of our multidisciplinary nutrition team (MZPmedical and HR-dietitian) for eligibility. At entry, the patient's age, main diagnosis, presence of other morbid conditions, weight, and height were recorded and the body mass index (BMI) was derived $\left(\mathrm{kg} / \mathrm{m}^{2}\right)$. Body composition was estimated in terms of body fat and muscle by measuring triceps skinfold thickness and mid-arm muscle circumference, using 
Holtain skinfold calipers and an inelastic tape on the non-dominant arm, as previously described. ${ }^{67}$ At entry (after discussion with the team caring for the patient and taking into account the nature of the underlying disease and all available clinical information), a prediction was made as to whether PEG feeding would be required only for a few weeks to months or for an indefinite period. PEG tubes used for this study were the $1.9 \mathrm{~mm}$ inner $2.9 \mathrm{~mm}$ (9F) outer diameter (Fresenius, Homberg, Germany) and the $3.0 \mathrm{~mm}$ inner $4.0 \mathrm{~mm}(12 \mathrm{~F})$ outer diameter tube (Bower, Corpac, Wheeling, IL, USA), both made of polyurethane. To ensure a standard procedure of PEG insertion, all endoscopists underwent a period of training before participating in the study, using each type of tube on at least five occasions.

PEG insertion was carried out under intravenous sedation, as previously described, ${ }^{8}$ and antibiotic prophylaxis was given in the form of a single dose of $1.5 \mathrm{~g}$ intravenous cefuroxime, or gentamicin $80 \mathrm{mg}$ in penicillin sensitive patients. At the end of the procedure a verbal explanation and a standard instruction sheet (available on request) covering nursing care of the PEG was given to an accompanying nurse from the patient's ward. In case of problems, ward staff were encouraged to contact a named person from the nutrition team. No further training was given to hospital nursing staff and patients were cared for on general wards. Outpatients were admitted for one to two days after PEG insertion, for training in the care of the device. They (or a family member) were instructed in the care of the gastrostomy puncture site, and handling and flushing the tube. After insertion, the gastrostomy feeding tube was not used for six hours. In the absence of pain, pyrexia, tachycardia, or hypotension, 500 $\mathrm{ml}$ water was given at a rate of $85 \mathrm{ml} / \mathrm{h}$, for six hours. Feeding was commenced thereafter at $45 \mathrm{ml} / \mathrm{h}$ and was gradually increased to the rate indicated to provide the individual's daily energy requirement. The following feed preparations were used: Nutrison Standard, Nutrison High Energy, Fortisip (Cow and Gate, Trowbridge, Wiltshire, UK), Osmolite, Ensure Plus, Nepro, and Pulmocare (Abbott Laboratories, Maidenhead, Berks, UK).

Demands on nursing time were assessed in the following way: eight randomly selected patients with PEG and 12 patients being fed via a nasogastric tube on the same wards, were studied for seven days each. At the beginning of each nursing shift, the ward nurse caring for the study patient was asked to record on a chart all activities and the time taken (in minutes) in relation to PEG or nasogastric tube care. At the end of the shift they were asked to complete any details that might have been omitted during busy times.

\section{EVALUATION OF OUTCOME AND}

COMPLICATIONS

Patients were reviewed at one, two, and four weeks, and monthly thereafter, until PEG removal or death. At each follow up visit weight, triceps skinfold thickness, and midarm muscle circumference were measured and body mass index was derived, and the presence or absence of the following complications was recorded: infection of insertion site, episodes of septicaemia, evidence for aspiration pneumonia, onset of gastrointestinal disturbance (diarrhoea or vomiting), tube blockage, tube fracture, and leakage from tube connection points. At each review, patients and carers were asked to list any other adverse events. After death, case notes were reviewed in order to ascertain, as far as possible, the cause of death.

\section{PROSPECTIVE RANDOMISED COMPARISON OF} TWO PEG TUBES

Between November 1991 and January 1993, patients were randomised to receive either the 9F Fresenius or the 12F Bower PEG tube, after contraindications were excluded by diagnostic oesophago-gastroduodenoscopy. Feed was delivered either by continuous infusion over 20-24 hours, or in cases requiring only overnight supplemental nutrition (such as patients with cystic fibrosis) over eight to 10 hours. The feeding rate was controlled using an enteral feeding pump (Flexiflo pump, Abbott Laboratories, Maidenhead, Berks, UK).

The following variables were examined prospectively in respect of each tube: time taken for PEG insertion, local sepsis, frequency of blockage, leakage from tube connections, tube fracture, and ease of removal.

Statistical analysis was by the Student's paired $t$ test and the $\chi^{2}$ test, as appropriate. Yates's correction was used for the $\chi^{2}$ test, where indicated. The study was approved by the local ethics committee and written informed consent was obtained from patients or their next of kin.

\section{Results}

INDICATIONS FOR PEG AND DEMANDS ON NURSING RESOURCES

Over 26 months (November 1990-January 1993), two of 81 patients referred were not accepted because of current severe pneumonia. Two others were found at endoscopy to have gastric ulcer and one a gastric carcinoma and were excluded.

A total of 76 PEG tubes were inserted in 76 patients ( 37 men: median age 62 (range 18-99 years)) who were followed for a total 6887 patient days. Median (range) duration of PEG feeding was 93 days (3-785). Thirty patients $(40 \%)$ were aged over 70 years. Thirteen $(17 \%)$ were ambulant outpatients at the time of referral for PEG (eight cystic fibrosis, three motor neuron disease, one oesophageal dysmotility, one pancreatic insufficiency after pancreatitis). Two patients were residents of nursing homes and returned there on the day of PEG insertion. Nine inpatients $(12 \%)$ were transferred to nursing homes for long term care within a few weeks of PEG insertion. 
TABLE I Main diagnoses in patients with a percutaneous endoscopic gastrostomy (PEG) in a general hospital

\begin{tabular}{ll}
\hline Indication for PEG feeding & No of patients (\%) \\
\hline Cerebrovascular disease (stroke) & $39(51)$ \\
Persistent vegetative state & $11(14)$ \\
Cystic fibrosis & $12(16)$ \\
Motor neuron disease & $4(5)$ \\
Dementia with chronic confusion & $3(4)$ \\
Post major surgery & $2(3)$ \\
Anorexia & $2(3)$ \\
Chronic renal failure & $1(1)$ \\
Multiple sclerosis & $1(1)$ \\
Oesophageal dysmotility & $1(1)$ \\
Post pancreatitis & $1(1)$ \\
Total & 76 \\
\hline
\end{tabular}

TABLE II Demands on nursing time of percutaneous endoscopic gastrostomy (PEG) and nasogastric tube (NG) feeding. (Results are median (range): $\chi^{2}$ test (no significant differences))

\begin{tabular}{lcc}
\hline & NG tube & PEG \\
\hline No of patients & 12 & 8 \\
Total no of patient days & 84 & 56 \\
No of tubes per 7 days & $2(1-4)$ & 1 \\
Flushing (min/day) & $4(1-10)$ & $8(1-40)$ \\
Total time (min/day) & $16(4-40)$ & $21(4-42)$ \\
$\begin{array}{l}\text { Time replacement or PEG } \\
\text { blocked (min/day) }\end{array}$ & $31(12-36)$ & $23(5-42)$ \\
\hline
\end{tabular}

None of the hospital inpatients at entry returned home. Forty patients $(53 \%)$ were severely malnourished at the time of referral (body mass index $<17 \mathrm{~kg} / \mathrm{m}^{2}$ ). Stroke was the most common indication for PEG $(51 \%$ cases) and neurological reasons accounted for $76 \%$ of all patients entered (Table I). In two cases the PEG was inserted for anorexia in addition to other medical problems (one chronic renal failure on haemodialysis, one congestive cardiac failure) because it was felt that poor nutrition was delaying recovery. The median (range) duration of hospital stay before PEG insertion was 21 days (1-306). The last patient entered was followed for two months before the results were analysed. Twenty three of 39 patients $(61 \%)$ with stroke were referred less than four weeks after admission to hospital and $32 \%$ between one and three months. At the time of referral for PEG, the body mass index was less than $17 \mathrm{~kg} / \mathrm{m}^{2}$ in six $(15 \%)$ stroke patients, all 12 cystic fibrosis patients, three of four motor neuron disease patients, and in most patients with other diagnoses.

There was no significant difference in the time spent caring for PEG and nasogastric tube patients. In five of 12 of the latter cases, the nasogastric tube was replaced at least once during the seven day period of observation (Table II). A total of 20 nasogastric tubes were required for 12 patients over seven days.

\section{EVALUATION OF OUTCOME AND}

COMPLICATIONS

Sixty five patients $(85 \%)$ were fed for more than two weeks, $55(72 \%)$ for more than four weeks, and $33(43 \%)$ for more than three months. Weight increased in all severely malnourished patients fed for four weeks $(n=25)$ median $2.5 \mathrm{~kg}$ (range $0.5-7$ ), as did the body mass index $(n=14)$ and mid-arm muscle circumference $(n=18)$ (Table III). In $12(16 \%)$ cases, swallowing recovered sufficiently to allow removal of the PEG after a median (range) period of 55 (20-150) days. Of these patients, only six had been predicted at entry as reversible. In all cases, PEG feeding continued until recovery or death. There were 11 deaths (15\%) within two weeks of PEG insertion, 20 $(26 \%)$ by one month, $24(31 \%)$ at two months, and $25(33 \%)$ by three months. Twelve of the 25 deaths were from pneumonia, four from progression of stroke, two septicaemia (not PEG related), one myocardial infarction, two motor neuron disease, one pulmonary embolus, and one renal failure.

There was one death from acute upper gastrointestinal haemorrhage eight days after PEG insertion, in a patient with end stage cystic fibrosis. Emergency endoscopy during life and detailed postmortem examination of the area of PEG insertion failed to disclose the source of bleeding. One death in a 92 year old man, was related to PEG insertion: at diagnostic endoscopy before insertion, a pharyngeal pouch was perforated. He was treated with intravenous antibiotics and fluids. Despite initial clinical improvement, he died of bronchopneumonia 12 days later. One patient complained of severe abdominal pain immediately after PEG insertion and developed signs of peritoneal irritation and ileus. This resolved on conservative treatment with intravenous antibiotics and fluids for $\mathbf{4 8}$ hours. One patient developed basal pneumonia five months after PEG feeding began and this was attributed to aspiration of feed. Pneumonia recurred after three weeks (despite ensuring that the patient was kept in a sitting position while feeding and the rate of infusion slowed) and PEG was considered to be the cause of death (Table IV).

There were few minor complications of PEG. In two patients (2\%) there was infection at the PEG insertion site at 77 and 150 days after the procedure. There were six episodes of diarrhoea in six patients $(8 \%)$ in the first 30 days of PEG feeding which resolved with simple measures (Table IV). Clostridium difficile was detected in the stool of two of these, but $C$ difficile toxin was absent. Two

TABLE III Anthropometric data on severely malnourished patients (body mass index (BMI) $<17 \mathrm{~kg} / \mathrm{m}^{2}$ ) at study entry and at four, eight, 12, 16, and 22 weeks from insertion of percutaneous endoscopic gastrostomy. Values are mean (SEM)

\begin{tabular}{|c|c|c|c|c|c|c|}
\hline & $\begin{array}{l}\text { Week } 0 \\
(n=40)\end{array}$ & Week 4 & Week 8 & Week 12 & Week 16 & Week 22 \\
\hline $\begin{array}{l}\text { No of paired values } \\
\text { BMI }\left(\mathrm{kg} / \mathrm{m}^{2}\right) \\
\text { No of paired values } \\
\text { MAMC } \\
\text { No of paired values } \\
\text { TST }\end{array}$ & $\begin{array}{l}15 \cdot 4(0 \cdot 2) \\
18 \cdot 8(0 \cdot 6) \\
10 \cdot 1(1 \cdot 0)\end{array}$ & $\begin{array}{l}14 \\
17 \cdot 2(0 \cdot 9)^{\star} \\
18 \\
19 \cdot 0(0 \cdot 7)^{\star} \\
18 \\
11 \cdot 7(1 \cdot 5)\end{array}$ & $\begin{array}{l}12 \\
18 \cdot 3(0 \cdot 9)^{\star} \\
18 \\
19 \cdot 2(0 \cdot 6)^{\star} \\
20 \\
11(1 \cdot 4)\end{array}$ & $\begin{array}{l}9 \\
18 \cdot 5(0.9)^{\star} \\
10 \\
21(0 \cdot 7) \dagger \\
13 \\
9 \cdot 2(0.8)\end{array}$ & $\begin{array}{l}8 \\
19 \cdot 8(1 \cdot 1)^{\star} \\
6 \\
20 \cdot 6(1 \cdot 6) \\
9 \\
11 \cdot 3(1 \cdot 4) \dagger\end{array}$ & $\begin{array}{l}8 \\
23 \cdot 2(4 \cdot 7) \\
7 \\
21(1 \cdot 1)^{\star} \\
7 \\
12(2 \cdot 0)\end{array}$ \\
\hline
\end{tabular}

MAMC $=$ mid-arm muscle circumferance; TST $=$ triceps skinfold thickness. Paired $t$ test ${ }^{\star} \mathrm{p}<0 \cdot 05,+\mathrm{p}<0 \cdot 02$ 
TABLE IV Early (<30 days) and late >30 days) deaths related to percutaneous endoscopic gastrostomy (PEG), number of patients with major and minor complications, and mechanical problems, during a total of 6887 patient days of observation in 76 patients with PEG. Number of episodes in brackets

\begin{tabular}{lll}
\hline & \multicolumn{2}{l}{ Time } \\
\cline { 2 - 3 } & $<30$ days & $>30$ days \\
\hline $\begin{array}{l}\text { Procedure related deaths: } \\
\text { Oesophageal perforation } \\
\text { Haemorrhage }\end{array}$ & 1 & 0 \\
$\begin{array}{l}\text { Other } \\
\text { Aspiration pneumonia }\end{array}$ & 1 & 0 \\
$\begin{array}{l}\text { Major complications: } \\
\text { Peritonism/ileus }\end{array}$ & 0 & 1 \\
$\begin{array}{l}\text { Minor complications: } \\
\text { Diarrhoea }\end{array}$ & 1 & 0 \\
$\quad \begin{array}{l}\text { Vomiting } \\
\text { PEG site infection }\end{array}$ & 6 & $2^{\star}$ \\
$\begin{array}{l}\text { Mechanical problems: } \\
\text { Blockage }\end{array}$ & 4 & 1 \\
Leakage & 0 & 2 \\
\hline
\end{tabular}

${ }^{\star}$ Clostridium difficile toxin positive.

patients developed diarrhoea after 30 days and $C$ difficile toxin was found in the stool of both cases. Both responded to antibiotic therapy. Nausea and vomiting occurred in five cases, four in the first 30 days, but all responded to simple measures.

Mechanical complications comprised nine episodes of tube blockage in six patients and five episodes of leakage in four patients. In all cases the blockage was cleared by flushing or the cautious use of a stiff guide wire, ensuring that the length of wire inserted did not exceed the length of PEG through the abdominal wall. Numbered graduations (in $\mathrm{cm}$ ) along the length of the PEG tube, made this easier. There were no complications in any of our patients whose tubes had been unblocked by this method. Blockage often followed failure to flush the tube between feeds and before and after the administration of drugs. There were no instances where the PEG was removed or replaced because of blockage. All episodes of blockage occurred in hospital inpatients or residents of nursing homes. No blockages occurred in any of the 13 cases (ambulant or outpatients) who cared for the PEG themselves or when care was provided by a family member. All episodes of leakage occurred in the $12 \mathrm{~F}$ (Bower) tube (Table V).

PEG related deaths and complications are summarised in Table IV.

\section{COMPARISON OF TWO PEG TUBES}

During 15 months (November 1991-January 1993), 29 patients were randomised to receive the $9 \mathrm{~F}$ tube and 27 the $12 \mathrm{~F}$ PEG tube. Follow up was conducted for two months after the last patient was entered at which time the results were analysed. There was no difference in the time taken for PEG insertion, Median (range) $21(10-45) v 24(10-45)$ minutes respectively, patient days followed (total $2920 v 2388$ days respectively), distribution of diagnoses, patient age $56(18-95) v 57(21-99)$ respectively, or the number of deaths (nine $v 14$ respectively). The number of patients with minor complications was not significantly different, although the total number of episodes of minor
TABLE V Complications with two percutaneous endoscopic gastrostomy (PEG) tubes ( $9 F$ compared with $12 F$ outer diameter)

\begin{tabular}{lll}
\hline & $9 F$ tube & $12 F$ tube \\
\hline No of patients & 29 & 27 \\
PEG blocked & 1 (2 episodes) & 5 (7 episodes) \\
Site infection & 2 & 0 \\
Septicaemia & 0 & 0 \\
Tube connector leak & 0 & $4(5$ episodes) \\
Tube fracture & 1 & 0 \\
Total no of patients with & 3 & 8 \\
$\quad$ complications & 3 & $12^{\star}$ \\
Total no of episodes & 3 & \\
\hline
\end{tabular}

${ }^{\star} \mathrm{p}<0.01, \chi^{2}$ test with Yates's correction.

mechanical problems was greater in the $12 \mathrm{~F}$ Bower group (Table V). Five of these episodes were due to leakage from the feeding tube-hub connector system. In one case (9F, Fresenius), fracture of the tube occurred near the hub and this was rectified by shortening the tube and replacing the hub. There were seven instances of blockage in five patients in the $12 \mathrm{~F}$ and two episodes in one patient in the $9 \mathrm{~F}$ group. No PEG was removed or replaced because of blockage. Three patients from the $9 \mathrm{~F}$ (Fresenius) group recovered sufficiently to allow removal of the tube by endoscopy, while in five of six patients, the $12 \mathrm{~F}$ (Bower) tube was removed non- endoscopically.

\section{Discussion}

Previous prospective studies of PEG in hospital patients reported its use in selected groups, such as those in persistent vegetative states, ${ }^{5}$ the elderly, ${ }^{9}$ patients with neurological problems in teaching hospitals, ${ }^{10}$ or young patients with cystic fibrosis. ${ }^{11}$ This study indicates that using our inclusion criteria, in a patient population from a district general hospital, stroke accounts for half of all cases in whom PEG may be employed, while neurological causes as a whole account for three quarters. Two thirds of stroke patients were referred within four weeks of hospital admission and only a small proportion of these were severely malnourished at the time of referral. In this group, there was no correlation between longer hospital stay before PEG and the degree of malnutrition. These findings suggest that in stroke patients delayed referral was not a major problem. The high proportion of severely malnourished patients in the cystic fibrosis, motor neuron disease, persistent vegetative state, and other groups suggests that earlier referral for PEG could have been considered. The number of cystic fibrosis patients in our series is higher than would be expected for a district general hospital, because of the regionally funded cystic fibrosis unit at Heartlands Hospital.

Nutritional improvement occurred in all severely malnourished patients who were fed for four weeks via PEG, as evidenced by increased weight, body mass index, and midarm muscle circumference. This finding supports results from previous studies which showed clear nutritional benefit from PEG compared with nasogastric tube feeding. ${ }^{510}$ Park et $a l,{ }^{5}$ reported greater weight gain with 
PEG than nasogastric tube feeding in the first week. This finding was attributed to greater dietary intake during uninterrupted periods of feed administration. Interruptions to nasogastric tube feeding were common because of tube displacement. ${ }^{51013}$ Our data on demands on nursing time for PEG and nasogastric tube feeding suggest that while there was no difference in the time spent in the routine care of the PEG and nasogastric tube, the frequent need for replacing the latter should result in a greater overall demand on nurses time by nasogastric tube feeding. The absence of a significant difference between the two in our study probably reflects a bias introduced by a short period of observation of seven days. An additional expense in the case of nasogastric tube feeding is the cost of radiology, which is often needed to confirm the position of a replaced tube.

The low incidence of mortality (4\%) and major complications $(2 \%)$ and the low frequency of minor complications in our study compare favourably with results from prospective studies in teaching hospitals ${ }^{10}$ and in highly selected patient groups, 5910 and agree with data from large retrospective series of general patient populations. ${ }^{24}$ The long term outcome in our patients is broadly similar to results of an audit of outcome reported by Hull et al from a series of 49 patients, ${ }^{12}$ although there are some important differences. In particular, the higher 30 day mortality in the present series $(26 \%$ compared with $8 \%$ in Hull's series) probably reflects patient selection. This is suggested by the fact that in Hull's study, 34 of $49(69 \%)$ patients entered were able to return home, while in our series, with the exception of the $13(17 \%)$ cases who were outpatients at the time of entry, all remained in hospital or were transferred to a nursing home.

In as many as $16 \%$ of patients the primary reason for PEG insertion resolved sufficiently to enable removal of the PEG. This was predicted correctly in only half of the patients. In our assessment of predictability we did not use predefined criteria because we had anticipated a diversity of problems in individual patients with varying severity of disease. In future studies it may be worthwhile to examine the usefulness of predefined criteria in predicting recovery. Our observation of poor predictability suggests that (at least until reliable predictors of reversibility can be identified) wider consideration should be given to PEG tubes that allow non-endoscopic removal, in order to minimise demands on resources and the small but finite risk of complications arising from a second endoscopy. The increasing practice of using 'exchange' gastrostomy tubes inserted by the 'push' technique through an already established fistulous tract, is an additional reason for preferring a non-endoscopically removable tube. In choosing between the 9F (Fresenius) and the 12F (Bower) tubes, the comparative costs of these devices must be taken into account. Although prices may vary between countries, in the United Kingdom the costs of the Fresenius $(9 F)$ and the Bower $(12 F)$ tubes are $£ 35.00$ and $£ 82.00$ (exclusive of value added tax) respectively.

We have become aware that some endoscopists avoid a second endoscopy for removal of the 9F Fresenius tube by cutting it at the skin and allowing the intragastric anchor to pass through the pylorus and finally in the stool. This is not our practice because we consider that inherent in this method is a small risk of small bowel obstruction (especially if there is unsuspected stricture) or entrapment in a diverticulum, which may result in erosion or perforation of the bowel.

Two patients with complications merit further discussion. The first, died of aspiration pneumonia five months after PEG insertion. Although we include him in our death rate of $4 \%$, it is debatable whether this death was directly attributable to PEG, since aspiration pneumonia is not uncommon in bed-ridden debilitated patients, whether fed by mouth, nasogastric tube, or PEG. It is possible that gastro-jejunostomy tube feeding may reduce the risk of aspiration. The second, is the patient with cystic fibrosis who developed peritonism and ileus after PEG insertion. We believe that this was due to laceration of the stomach during the insertion procedure. This risk could be reduced by more generous sedation and analgesia, while monitoring oxygen saturation by pulse-oximeter. We have discussed this case in detail in a previous letter. ${ }^{14}$

Mechanical complications identified were tube blockage and leakage. Inquiry into the circumstances under which these occurred, suggested that the former was due to inadequate flushing of the tube between feeds and before and after drug administration. This problem seemed to be common on long stay wards with a low ratio of nurses to patients. In this context, it is interesting that there were no instances of tube blockage where patients or family members were caring for the PEG. Better education and training of nursing staff in the care of PEG (in addition to the minimum given in the present study) or using a nurse specialist in nutrition, or both, could reduce the frequency of tube blockage. Tube blockage was more common (though not significantly) with the wider diameter $12 \mathrm{~F}$ Bower tube but this seemed to be related to poor nursing care rather than to an intrinsic problem with the device. Consistent with this interpretation is the observation that seven of nine episodes of blockage occurred in the first month of PEG feeding, and rarely recurred later (Table IV). Leakage was a problem encountered with the Bower tube at the site of the tube connection to the hub. This was because of a defect in the tube-hub connector device which was rectified by the manufacturer and the problem was not encountered in the latter part of our series. Nevertheless, this resulted in a statistically significant increased frequency of minor mechanical problems in the Bower group.

The technical procedure of PEG insertion was equally easy with the $12 \mathrm{~F}$ Bower and the 9F Fresenius tubes and we did not encounter specific problems with either. With increasing experience, in the latter part of the study, the 
time taken to complete the procedure rarely exceeded 15 minutes.

PEG feeding is effective in a general hospital population and can be of benefit in patients requiring feeding for only a few weeks. Further prospective studies to assess the predictability of recovery may be helpful in the choice of PEG tube design.

This study was supported by E Merck Pharmaceuticals, Alton, Hants, UK, distributors of the Bower PEG system.

1 Gauderer MWL, Ponsky JL, Izant RJ (Jr). Gastrostomy without laparotomy: a percutaneous technique. 7 Pediat Surgery 1980; 15: 872-5.

2 Ponsky JL, Gauderer MW, Stellato TA. Percutaneous endoscopic gastrostomy: a review of 150 cases. Arch Surg 1983; 118: 913-4.

3 Kirby DF, Craig RM, Tsang TK, Plotnick BH. Percutaneous endoscopic gastrostomies: a prospective evaluation and review of the literature. Fournal of evaluation and review of the literature.

4 Larson DE, Burton DD, Schroeder KW, DiMagno EP Percutaneous endoscopic gastrostomy. Indications, Percutaneous endoscopic gastrostomy. Indications,
success, complications and mortality in 314 consecutive success, complications and mortality in 314

patients. Gastroenterology 1987; 93: 48-52.
Wicks C, Gimson A, Vlavianos P, Lombard M, Panos M, Macmathuna $\mathrm{P}$, et al. Assessment of the percutaneous endoscopic gastrostomy feeding tube as part of an integrated approach to enteral feeding. Gut 1992; 33 613-6.

6 Thomas B. Manual of dietetic practice. Oxford: Blackwell Scientific, 1988.

7 Bishop CW, Ritchey SJ. Estimation of the mid-upper arm circumference measurement error. F Am Diet Assoc 1987; 87: 469-73.

8 Russell TR, Brotman M, Norris F. Percutaneous gasrostomy. A new simplified and cost-effective technique. Am F Surg 1984; 148: 132-7.

9 Finucane P. Aslan SM, Duncan D. Percutaneous endoscopic gastrostomy in elderly patients. Postgrad Med $\mathcal{F}$ 1991; 67: 371-3.

10 Park RHR, Allison MC, Lang J, Spence E, Morris AJ, Danesh BJZ, et al. Randomised comparison of percutaneous endoscopic gastrostomy and nasogastric percutaneous endoscopic gastrostomy and nasogastric
tube feeding in patients with persisting neurological tube feeding in patients with persi

11 Poole S, Lombard M, Gimson AE, Hodson M, Westaby D. Gastrostomy feeding in cystic fibrosis patients with severe lung disease. Thorax 1993; 48: 442.

12 Hull MA, Rawlings J, Murray FE, Field J, McIntyre AS Mahida YR, et al. Audit of outcome of long-term enteral nutrition by percutaneous endoscopic gastrostomy. Lancet 1993; 341: 869-72.

13 Abernathy GB, Heizer WD, Holcombe BJ, Raasch RH, Schlegel KE, Hak LJ, et al. Efficacy of tube feeding in supplying energy requirements of hospitalised patients. supplying energy requirements of hospitalised patients. fournal of Parenteral and Enteral Nutrition 1989; 13:

14 Panos MZ, Moran A, Stableforth D, Chesner I. Percutaneous endoscopic gastrostomy in elderly patients [letter]. Postgrad Med f 1992; 68: 936. 